\title{
Optimising flow management for ecological response and consumptive use
}

\author{
$\underline{\text { S.J. Powell }}^{\mathrm{a}}$, S.J. Nichols ${ }^{\mathrm{a}}$, J.A. Webb ${ }^{\mathrm{b}}$, G. Adams ${ }^{\mathrm{c}}$, S.C. de Little ${ }^{\mathrm{b}}$, and B. Dyack ${ }^{\mathrm{a}}$ \\ ${ }^{a}$ Murray Darling Basin Futures Collaborative Research Network, Institute of Applied Ecology, University of \\ Canberra, Australian Capital Territory \\ ${ }^{b}$ Department of Resource Management and Geography, The University of Melbourne, Victoria \\ ${ }^{c}$ eWater Ltd, Innovations Centre, University of Canberra, Australian Capital Territory \\ Email:sue.powell@canberra.edu.au
}

\begin{abstract}
The regulation of flow in river systems and use of water for consumptive and economic purposes has led to detrimental effects on riverine, wetland and floodplain environments in river systems worldwide. In recent years, there has been a concerted effort to develop policies to return water to the environment to minimise these effects. However, there are far fewer instances of actual flows being delivered. One barrier to the delivery of environmental flows is the need to balance environmental and consumptive outcomes, optimising returns for both with a limited volume of water. Various methods are available to help define the flows required to protect specific ecological assets or to mimic aspects of natural flow regimes, but few consider consumptive uses as part of the same set of calculations.
\end{abstract}

In this paper, we present a method of evaluating flow options using ecological response models incorporated into daily hydrology and irrigation river management models. A multi-objective optimisation approach produces the Pareto frontier of non-dominated solutions, which provides decision makers with a range of alternative optimal management options.

An integrated water resource model of the Goulburn River, Victoria, Australia, is developed that represents the rivers, water storages, operational constraints, water management and consumptive demands on a daily time-scale linked to climate. Models of ecological responses to flow are incorporated into the river model to simulate ecological response and generate environmental flow demands. Storage volumes are used to determine water allocations which in turn determine the area irrigated and relative value of the crop mix. We develop this eco-hydrology model and optimisation approach as a 'proof of concept' example, where the objective functions are to minimise terrestrial vegetation encroachment into the main river channel through the use of environmental flows, while maximising the net relative value of irrigation.

The model is run over 35 years and the results indicate that a range of optimal solutions exist. In the best case for irrigation there is a net relative value (over the 35 years) of almost $\$ 17 \mathrm{~B}$ while terrestrial vegetation encroachment could average approximately $13 \%$. In contrast, it would be possible to reduce the terrestrial vegetation encroachment to just $2 \%$, however, this would reduce net relative value of irrigation to around $\$ 12 \mathrm{~B}$. Interestingly the latter option would also result in some short-term periods of very high vegetation encroachment. This was because of much lower overall storage volumes resulting in $0 \%$ water allocations in some years. Our results highlight the importance of hydrological modelling of both consumptive use and ecological response to understand the feedback mechanism of some management decisions. Between the two extremes are a range of results that provide a clear understanding of what outcomes could be expected for both of the objective functions for all optimised solutions.

The results presented in this paper are applied to a simple representation of the Goulburn River with limited model testing to illustrate the concept and value of integrating ecological response models into hydrological river management models, and how multi-objective optimisation tools can be applied to water management issues. The hydrological feedback loops that occur when environmental flows and consumptive water are ordered and delivered can be complex. Therefore the eco-hydrology and allocation systems must be modelled concurrently to understand the implications and trade-offs involved in managing water allocations.

Keywords: Ecology, modelling, hydrology, optimisation, environmental flows 


\section{INTRODUCTION}

Water resource development is increasing world-wide and the Murray-Darling Basin in Australia is no exception. Over the last century the development of the Murray-Darling system has included the building of weirs, regulating structures and water storages. Initially to provide a navigable river and water security for stock and domestic use, the development escalated in the latter half of the $20^{\text {th }}$ century to provide improved reliability of water supply for irrigation, urban supplies and industry. The regulation of river systems and extraction of water for irrigation and industry has led to detrimental impacts on riverine, wetland and floodplain environments (Kingsford, 2000; Walker, 1985). In recent years concerted efforts have focused on providing flows to minimise these adverse environmental impacts (Murray-Darling Basin Authority, 2012).

A range of objective-based methods have been developed to define the flows required for particular river reaches or ecological assets (Tharme, 2003). Ecological response models, which can include input from unquantified expert opinion, experimental datasets and process models (Young et al., 2003), seek to predict or assess the ecological outcomes of different volumes and timing of flows, and help identify trigger points to initiate provision of environmental flows (Cogle et al., 2010). Scenario-based and decision support systems can provide for assessment of trade-offs and discussion between stakeholders (Acreman and Dunbar 2004). Regardless of the approach, most efforts to define and deliver environmental flows focus on modelling a particular level of benefit for the ecology, and its cost in terms of loss of income from consumptive and other economic uses.

An approach proposed by Grafton et al. (2011) focused on optimising delivery of flows to provide the best overall outcomes for both the ecological assets and consumptive and other economic uses. The approach used ecological functions that relate ecological outcomes to flow metrics. Similarly, consumptive and other economic use can relate factors such as crop yield or energy production (hydroelectricity) to flow metrics. Grafton et al. (2011) developed a dynamic stochastic model to incorporate current weather and weather correlation to determine water availability and drought status. The approach converted the ecological objectives to a scalar (dollar) value to reduce the complexity of the problem and enable the calculation of a single 'optimal' solution between the ecological value and agricultural profit. Although it operated on a vastly simplified model of the catchment and its ecology and economics, the model demonstrated that optimisation is possible.

Problems with the ecological valuation approach employed by Grafton et al. (2011) are well documented (Carpenter and Turner, 2000; Chavas, 2000; Costanza, 2000; Ludwig, 2000). The value or weighting applied can vary with the solicitation method used, who is asked and even when preferences are solicited (Kennedy et al., 2008). The ecology-agriculture trade-off may thus be better conceptualized as a multi-objective optimisation problem (Cui et al. 2011). For a multi-objective problem there is usually no single optimal solution. The Pareto optimality approach seeks to find the best set of alternative solutions (Cui et al., 2011) such that, for objectives Z1 and Z2, any improvement in Z1 comes at a cost to Z2 and vice-versa. The nondominated Pareto frontier provides decision makers with a range of optimal alternatives before any weightings are applied (Kennedy et al., 2008). This method enables visualisation of the trade-offs amongst objectives and may provide a better basis for further non-market valuation and to aid decision making.

In this paper, ecological-response-to-flow models and traditional climate-based irrigation models are integrated using the eWater Source Integrated Water Resource Modelling software (Carr and Podger, 2012; Welsh et al., 2012). We use the Source model to simulate inflows, system operations, ordering rules (consumptive and other economic uses, environmental flows) and climate variables in a 'proof of concept' using a simplified representation of the Goulburn River system in Victoria, Australia. We then used eWater's Insight optimisation tool to determine the non-dominated Pareto front of decision variables.

\section{METHODS}

\subsection{Source models}

The Source modelling platform (Carr and Rodger 2012, Welsh et al. 2012) simulates the physical and management aspects of river systems at a range of spatial and temporal scales. For our proof of concept model, we developed a Source model consisting of a daily time-step water system model incorporating water storage and regulation, lumped tributary inflows, flow routing and major diversions similar to those of the Goulburn River, Victoria, Australia (Figure 1). The model is a simplified representation of the system and does not attempt to replicate the complexity of a fully operational model. Despite this, the observed versus modelled flow near the end of the system (McCoy Bridge) is reasonable, particularly at the monthly time- 
step (r2 of 0.53 for daily and 0.80 for monthly flows using TVE target of 13\%). Further development would include more calibration and testing of the underlying hydrological models.
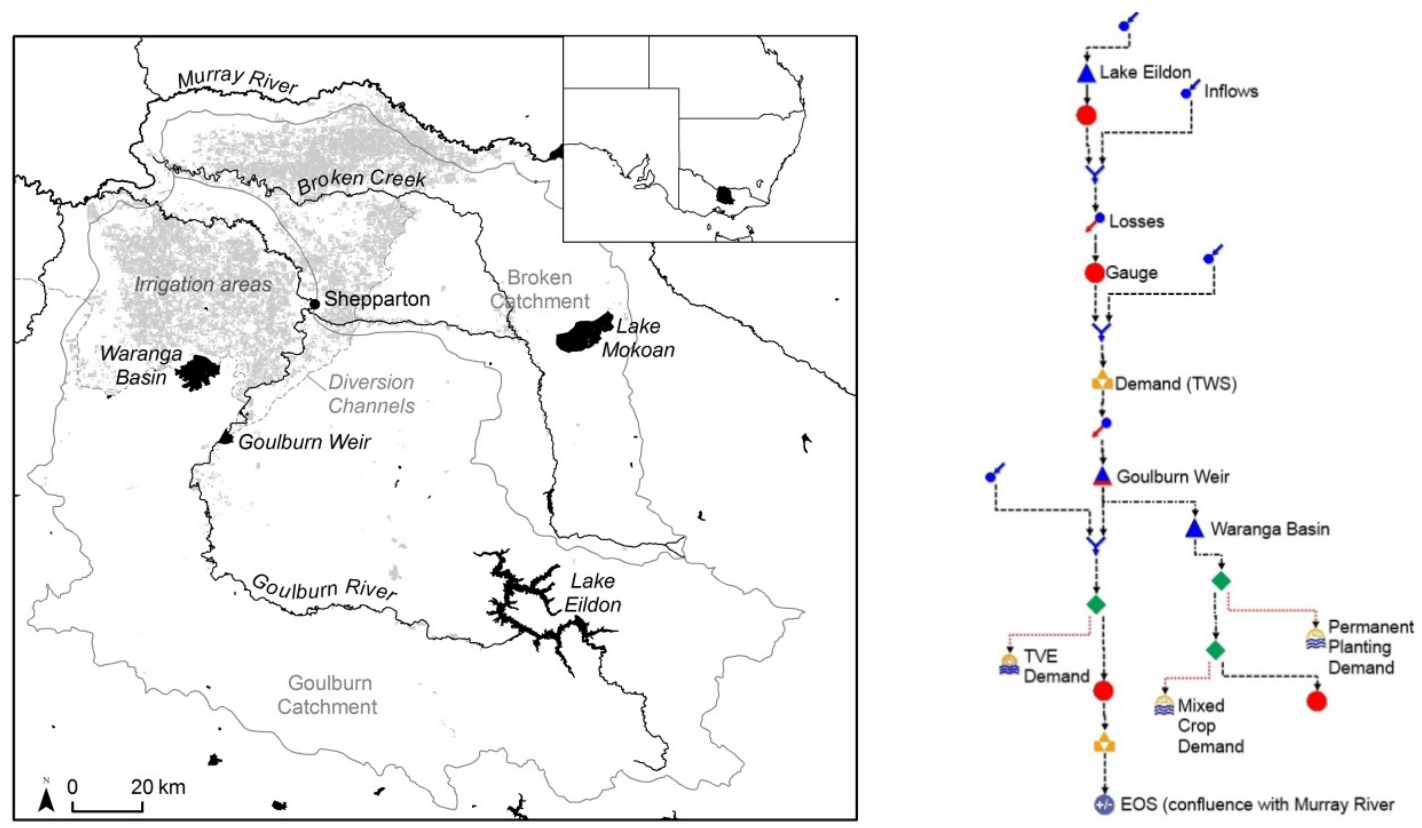

Figure 1: Goulburn-Broken catchment and the simplified Source model of the Goulburn system.

The river model includes the major water storages (Lake Eildon, Goulburn Weir and Waranga Basin) and two lumped irrigation developments of high security (permanent plantings and permanent dairy pasture) and general security development (cereal or annual crops). The irrigation size and allocation is representative of the Goulburn irrigation area but the distribution system is highly simplified. Irrigated area is represented in a simple net irrigation value model. The Source model also includes a town water supply, an end of system flow requirement and an ecological response model of terrestrial vegetation encroachment (TVE) downstream of Goulburn Weir. A simple annual accounting system is used whereby allocations for each water account are initially assessed on the 1 July each year based on available supply in Lake Eildon and can be updated as more water from inflows becomes available. There are no carryover provisions with accounts reset at the end of each water year. High security shares are given a higher allocation when resource is constrained. Daily flow, rainfall and evaporation data were provided by Victorian Department of Environment and Primary Industries for the Goulburn catchment for the period 1901 to 2012. Flow data included inflows to the main water storage (Eildon), two mid catchment flows representing the lumped tributary inflows to the main river channel and a lumped tributary inflow downstream of irrigation extractions, primarily from the Broken Catchment. Two sets of evaporation and rainfall data are included for the upper catchment and storage (Eildon) and lower catchment and irrigation areas (Waranga).

\subsection{Irrigation ordering and valuation}

Irrigation is represented through two extraction points representing a higher-security crop mix of permanent plantings (fruit and permanent pasture), and a general security crop mix of annual crops. The scale of development is in line with reported data on the Goulburn catchment where dairy is the predominant industry (Qureshi et al., 2012). Source provides a number of inbuilt irrigation demand models. This study uses Source's "Irrigator" crop water use model. Irrigator models crop water balance for each crop based on crop evapotranspiration (Allen et al., 1998). Irrigator also allows for planting decisions to be tailored. In this model, planting decisions are based on the simulated seasonal water allocations. The variables required for the irrigator module seek to represent 'typical' conditions for the southern Murray-Darling Basin. At the beginning of each planting season, an area is planted. Each day soil moisture deficit is calculated from the crop demand model and climate data and water orders are placed from Eildon Storage. If available, the water is released and then extracted after appropriate delay interval for travel time.

A simple representation of net profit of each crop is calculated from the area planted assuming yield is unaffected by climatic variables other than water availability. The input costs (including capital and variables), crop prices and yield for each crop are calculated over the area planted, plus a fixed pumping cost of $\$ 20 \mathrm{ML}^{-1}$ (Qureshi et al., 2012). Water pricing or trading are not currently included in this model. As the 
Powell et al., Optimising flow management for ecological response and consumptive use

major irrigation activity in this region is perennial pastures for diary, some assumptions were made in converting area of pasture to litres of milk produced (Khan et al., 2010).

\subsection{Ecological response function:}

Developing quantitative relationships between flow and ecological response is challenging. A recent review of 165 papers by Poff and Zimmermann (2010) found that while quantitative analysis provided some insight into flow-ecology relationships, robust statistical relationships were not apparent. Here, we used a more focused example. Terrestrial vegetation encroachment (TVE) into regulated river channels is an issue of importance to catchment managers in the Murray-Darling Basin, including the Goulburn River. TVE has the potential to reduce channel capacity and can modify fluvial ecosystem function (Power et al., 1996). Webb et al. (in review) used multiple lines of evidence to develop a general quantitative model relating cover of terrestrial vegetation within river channels to inundation history. First, an Eco Evidence causal criteria analysis found good support for the hypothesis that increased scouring and inundation can reduce terrestrial vegetation encroachment (Miller et al., in review) Second, expert opinion provided an initial quantification, suggesting that longer duration of inundation, particularly in winter, can reduce terrestrial vegetation cover, and grazing pressure also influences terrestrial vegetation (De Little et al., 2012). Finally, a Bayesian hierarchical model combined the Eco Evidence model structure and the expert-derived prior quantification of the relationships, with data collected under the Victorian Environmental Flows Monitoring and Assessment Program (Webb et al., 2010), to create the quantitative response function used here. The Bayesian hierarchical model was simplified to fit the model structure required for implementation in Source (1).

$$
\text { sqrt. } \text { cover }_{i}=\text { veg. } 0 * \exp \left(-m \frac{T_{i}}{f_{i}}\right)+\text { eff. season } * \text { win.rat }{ }_{i}+\text { eff. slope } * \overline{\text { slope }}
$$

Where veg. 0 is the sqrt of cover expected under zero inundation; $T$ is total number of inundation days over the last year; $f$ is number of events (with spell of $>5$ days); win.rat is the ratio of days that occur in winter (normalised); and $m$, eff.season and eff.slope are all location dependent parameters.

Central to the multi-optimisation question is how to order and deliver water to minimise TVE, and what decisions can be optimised. A simple adaptive management approach was used to demonstrate the concept. The decision to deliver water from storage for suppression of terrestrial vegetation within the channel is made on a day by day basis depending on the (modelled) TVE value. If the \%TVE exceeds some target value, the required amount of water to inundate the bank is ordered. Source then calculates whether the water is available and then how much to release from storage to meet that demand at that point. The decision variable to be optimised in this case is the \% TV target to initiate the water order.

\subsection{Optimisation}

The Source model forms the basis for the integrated eco-hydrological and water management modelling. eWater's Insight tool uses the non-dominated sorting genetic algorithm (NSGA II) to determine the range of Pareto-optimal solutions (Srinivas and Deb, 1995). The algorithm has two objectives, first to guide the search towards finding a non-dominated set of solutions as close as possible to the Pareto optimal front and second, to keep a diverse set of non-dominated solutions. The management 'levers' corresponding to the Pareto optimal front are the rules that are used to order water and any variables linked to water delivery. Here, the management lever is the modelled TVE that triggers an environmental release.

\section{RESULTS}

Insight optimisation was run for the simple Goulburn River Source model. The objective functions were to minimise the average terrestrial vegetation encroachment (\%) and to minimize the total (-ve) net value of crops (i.e. maximizing crop value). The optimisations were run for a 35 years period (1977-2012) with a population (for the genetic algorithm) of 100 over 100 generations. There were 36 suboptimal solutions removed, leaving a population of 64 . In this case, it appears that running the optimisation over 100 generations was close to optimal.

The Pareto front (Figure 2) showed a fairly predictable response with the best scenario for net value (S1) for irrigation of almost $\$ 17 \mathrm{~B}$, which equates to approximately $\$ 2360 \mathrm{ha}^{-1} \mathrm{yr}^{-1}$. In comparison with the top quartile of producers in a very high profit year for dairy industry in Victoria, Australia, of $\$ 2260 \mathrm{ha}^{-1} \mathrm{yr}^{-1}$ in $2010 / 11$ this estimate is a little high. This is most likely because no economic cost was factored into a loss of permanent plantings resulting from a drop in water allocations, however, it does serve well as a relative indicator. Under this scenario, the TVE was $13.1 \%$. Suppressing terrestrial vegetation through environmental flows can reduce the modelled TVE down to $2.5 \%$ (S2). To achieve this reduction, the net value for irrigation 
was just over $\$ 12 \mathrm{~B}\left(\$ 1680 \mathrm{ha}^{-1} \mathrm{yr}^{-1}\right)$, which is a substantial reduction in irrigation value due to water availability alone. The Pareto front of optimal solutions shows a fairly linear relationship between average terrestrial vegetation and net value for irrigation (Figure 2).

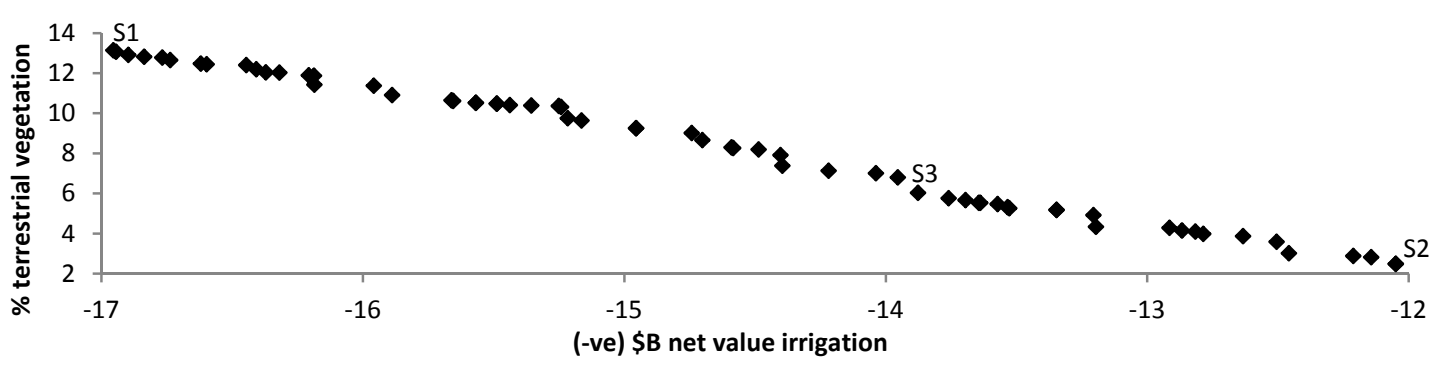

Figure 2: Pareto front showing the set of non-dominated solutions for \$TVE and net profit from irrigated agriculture

The optimisation seeks to minimise the long term average \%TVE, however, the \%TVE can vary greatly through time (Figure 3). The provision of flows can suppress terrestrial vegetation, although in the most extreme case where TVE is reduced to almost $2 \%(\mathrm{~S} 2)$ there are also times of dramatic increase in TVE (Figure 3). This occurs because all environmental entitlement is used in most years, which results in much lower storage volumes and $0 \%$ allocations in some years (Figure $4 \mathrm{a}$ ). The $0 \%$ allocations also mean a reduction in the areas of perennial pasture irrigated under the S2 example (Figure $4 \mathrm{~b}$ ).

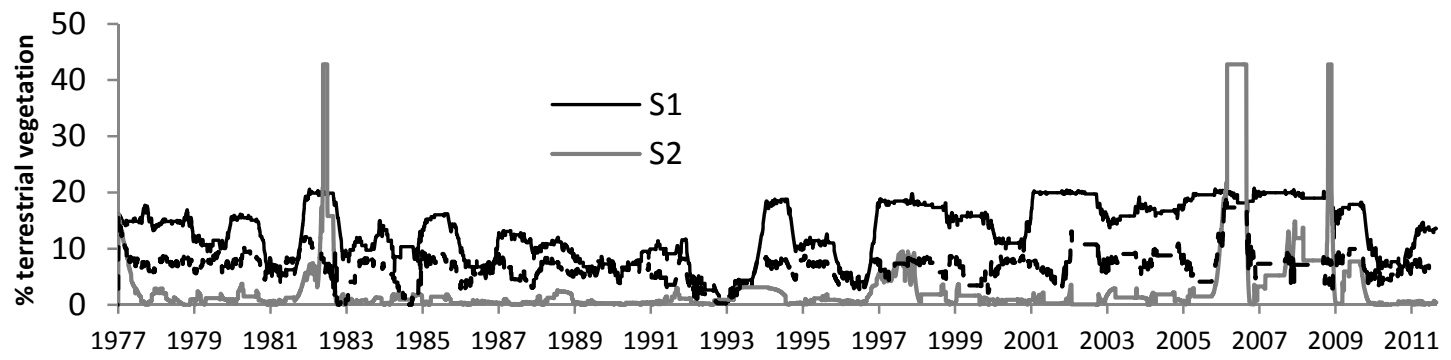

Figure 3: Daily modelled \% terrestrial vegetation encroachment TVE for three alternative optimal solutions in the Pareto front.
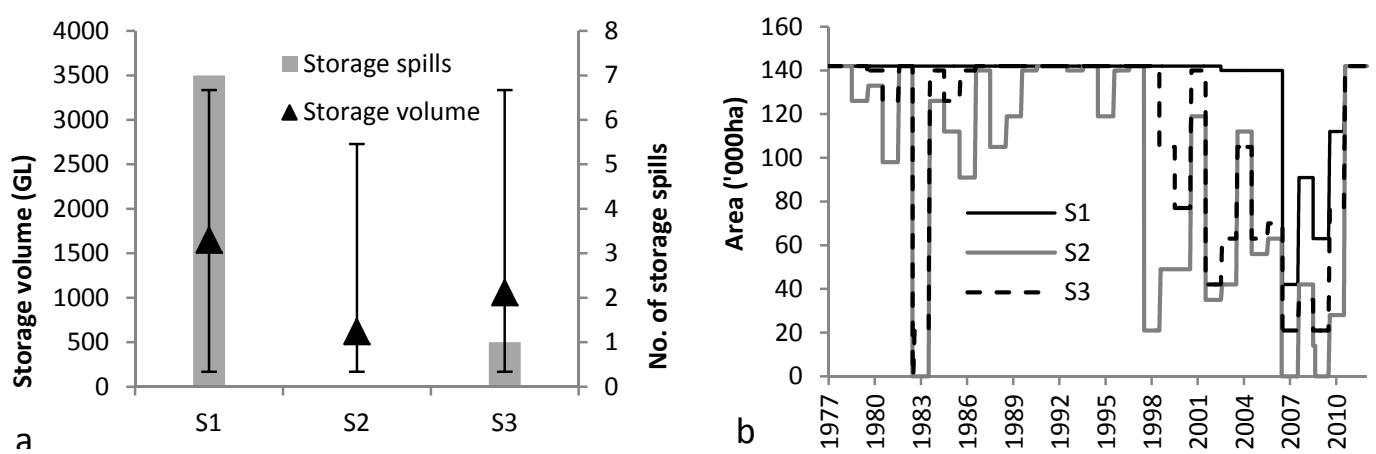

Figure 4: a) Storage volumes and number of spill events and b) area able to be irrigated each year for perennial pastures.

\section{DISCUSSION}

This model builds on the work of Grafton et al. (2011) by increasing the realism of the physical system (using Source) and increasing the realism of the ecological model (the terrestrial vegetation encroachment model). This model also uses multi-criteria optimisation instead of attempting to monetize ecological response in the first instance and so demonstrates the feasibility of optimisation of water management.

The results presented in this paper apply to a simple representation of the Goulburn River with limited model testing and requires further development of hydrological models, ecological models, and of the underlying economic assumption to be applied to river management decisions. However, they illustrate the value of 
integrating ecological response models into hydrological river management models, and demonstrate the application of optimisation tools to water management issues. The hydrological feedback loops that occur when environmental flows and consumptive water are ordered and delivered can be complex and therefore the eco-hydrology and allocation systems must be modelled concurrently to understand implications and trade-offs involved in managing water allocations.

In this modelled example, environmental water is ordered in response to ecological condition, which attempts to mimic an adaptive approach for the management of environmental flows (as opposed to a predetermined flow regime). In many ways this is similar to irrigation demand, where water is ordered in response to a predefined crop water deficit. In both instances the water demand is as a direct result of climatic conditions. The methods described in this paper could be used to evaluate a range of 'rules' including the allocation of unregulated tributary inflows, management of instream weir structures, allocations in wet versus dry years, timing and frequency of environmental flows and how and when storage releases are made.

To demonstrate the conceptual approach we used simple objective functions, that is, the average terrestrial vegetation encroachment and the net value of irrigation over the entire run period of 35 years. In the case of vegetation encroachment, the rules that result in the best long-term average TVE may not actually reflect the best outcome for the environment. The minimum and maximums or the length of time that particular targets are met may provide better environmental outcomes. The choice of the objective function should be considered in view of a more systems-based understanding of the ecological functioning of the riverine environment. Similarly, a single ecological value is unlikely to represent the best outcome for the entire system. Consideration should be given to multiple ecological response functions and the interaction between them. In the same way, economic indicators should consider shorter-term impacts (such as through drought periods) as well as long-term viability. Further development of more complex objective functions will improve utility of the model. The use of historical data and pure data-fitting models can be misleading because future scenarios may extend beyond past experience. There is a need to carefully consider the evidence for any hypothesis, the ecological basis for any results, and some consideration of outcomes beyond the available data. Further development of the concepts presented in this paper will include both multiple ecological response functions and a broader consideration of the riverine system as a whole.

Environmental flows theory and practice has developed in areas where rivers are fully or over-allocated to consumptive uses and flow recommendations have focused on returning sufficient water from consumptive use to sustain healthy riverine environments (Poff and Zimmermann, 2010). Implementation of recommendations are often not made in full because of economic and political pressure from consumptive and other economic demands for the water (Ladson and Finlayson, 2002). Trade-offs are generally made between the environment and consumptive use taking into account only the economic value of the consumptive use, however, the relative benefits that may accrue from providing a healthier environment should not be ignored. Eventually decision support systems operating on similar basic principles used in the model described here may help us move beyond constantly considering losses (e.g. lost productivity through environmental flows; lost environmental performance through consumptive use) to considering multiple benefits of water released from storages. These benefits can eventually be expressed in terms of overall social value allowing better assessment of trade-offs in relation to environmental, social and economic values.

\section{Acknowledgements}

This project is funded through the MDBfutures Collaborative Research Network while the terrestrial vegetation model development was funded through an ARC Linkage project (100200170). We would also like to acknowledge the assistance of the Victorian Department of Environment and Primary Industries and Goulburn-Murray Water for provision of hydrological data.

\section{REFERENCES}

Allen, R.G., Pereira, L.S., Raes, D., Smith, M., 1998. Crop ev apotranspiration. Guidelines for computing crop water requirement. FAO Irrigation and drainage paper 56. Food and Agriculture Organization of the United Nations: Rome.

Carpenter, S.R., Turner, M., 2000. Opening the Black Boxes: Ecosystem Science and Economic Valuation. Ecosystems 3(1) 1-3.

Carr, R., Podger, G., 2012. eWater Source - Australia's next generation IWRM modelling platform, 34th Hydrology and Water Resources Symposium December 2012.

Chavas, J.-P., 2000. Ecosystem Valuation under Uncertainty and Irreversibility. Ecosystems 3 11-15. 
Powell et al., Optimising flow management for ecological response and consumptive use

Cogle, L., Little, S., Lee, J., Swirepik, J., Hohnberg, D., Akeroyd, M., 2010. Ecosystem response modelling needs of the Living Murray Initiative, In: Saintilan, N., Overton, I. (Eds.), Ecosystem response modelling in the Murray-Darling Basin. CSIRO publishing: Melbourne, pp. 175-181.

Costanza, R., 2000. Social Goals and the Valuation of Ecosystem Services. Ecosystems 3 4-10.

Cui, L., Ravalico, J., Kuczera, G., Dandy, G., Maier, H., 2011. Multi-objective Optimisation Methodology for the Canberra Water Supply System. eWater Cooperative Research Centre: Canberra.

De Little, S.C., Webb, J.A., Patulny, L., Miller, K.A., Stewardson, M.J., 2012. Novel methodology for detecting ecological responses to environmental flow regimes: Using causal criteria analysis and expert elicitation to examine the effects of different flow regimes on terrestrial vegetation encroachment, In: Mader, H., Krami, J. (Eds.), 9th International Symposium on Ecohydraulics 2012 Proceedings: Vienna, Austria.

Grafton, Q.R., Chu, H.L., Stewardson, M., Kompas, T., 2011. Optimal dynamic water allocation: Irrigation extractions and environmental tradeoffs in the Murray River, Australia. Water Resources Research 47.

Kennedy, M.C., Ford, E.D., Singleton, P., Finney, M., Agee, J.K., 2008. Informed multi-objective decisionmaking in environmental management using Pareto optimality. Journal of Applied Ecology 45 181-192.

Khan, S., Abbas, A., Rana, T., Carroll, J., 2010. Dairy water use in Australia dairy farms: Past trends and future prospects. CSIRO Water for a Healthy Country National Research Flagship.

Kingsford, R.T., 2000. Ecological impacts of dams, water diversions and river management on floodplain wetlands in Australia. Austral Ecology 25 109-127.

Ladson, A., Finlayson, B., 2002. Rhetoric and reality in the allocation of water to the environment: A case study of the Goulburn River, Victoria, Australia. River Research and Applications 18 555-568.

Ludwig, D., 2000. Limitations of Economic Valuation of Ecosystems. Ecosystems 3 31-35.

Miller, K., Webb, J.A., de Little, S.C., Stewardson, M., in review. Environmental flows can reduce the encroachment of terrestrial vegetation into river channles: a systematic literature review. Environmental Management.

Murray-Darling Basin Authority, 2012. Basin Plan: Water Act 2007. Murray-Darling Basin Authority: Canberra.

Poff, N.L., Zimmermann, J.K.H., 2010. Ecological responses to altered flow regimes: a literature review to inform the science and management of environmental flows. Freshwater Biology 55 194-205.

Power, M.E., Dietrich, W.E., Finlay, J.C., 1996. Dams and downstream aquatic biodiversity: Potential food web consequences of hydrologic and geomorphic change. Environmental Management 20 887-895.

Qureshi, M.E., Mainuddin, M., Marvanek, S., Elmahdi, A., Conner, J., Whitten, S., 2012. Irrigation Futures for the Murray Basin - Technical Documentation, In: Flagship, C.W.f.a.H.C.N.R. (Ed.).

Tharme, R.E., 2003. A global perspective on environmental flow assessment: emerging trends in the development and application of environmental flow methodologies for rivers. River Research and Applications 19(5-6) 397-441.

Walker, K.F., 1985. A review of the ecological effects of river regulation in Australia. Hydrobiologia 125(1) 111-129.

Webb, J.A., de Little, S.C., Miller, K.A., Stewardson, M., Rutherford, I.D., Sharpe, A.K., Patulny, L., Poff, N.L., in review. Modelling ecological responses to environmental flows: making the best use of the literature, expert knowledge , and monitoring data., Proceedings of the 3rd Biennial Symposium of the International Society for River Science: Beijing, China.

Webb, J.A., Stewardson, M.J., Chee, Y.E., Schreiber, E.S.G., Sharpe, A.K., Jensz, M.C., 2010. Negotiating the turbulent boundary: the challenges of building a science-management collaboration for landscape-scale monitoring of environmental flows. Marine and Freshwater Research 61 798-807.

Welsh, W.D., Vaze, J., Dutta, D., Rassam, D., Rahman, J., Jolly, I., Wallbrink, P., Podger, G., Bethune, M., Hardy, M., Teng, J., Lerat, J., 2012. An integrated modelling framework for regualted river systems. Environmental Modelling \& Software 39 81-102.

Young, W.J., Scott, A.C., Cuddy, S.M., Rennie, B.A., 2003. Murray flow assessment tool - a technical description. Client Report, 2003. CSIRO Land and Water: Canberra. 